\title{
Developing a System for the Prediction and Management of Aircraft Deicing/Anti-icing Fluids Concentrations in Airport Effluents
}

\author{
Michael Most, Lowell Berentsen, Charlie Rodriguez and Billy Cheek \\ Southern Illinois University Carbondale
}

\begin{abstract}
Applications of aircraft deicing/anti-icing fluids (AD/AF's) are necessary for safe flight operations during winter storms. However, these compounds have been detected in both ground and surface waters, and field observations have demonstrated the detrimental effects of introducing such substances into the environment. Those who manage the application of these compounds are subject to contradictory, sometimes mutually exclusive, regulations. At approximately $50 \%$ of those airports where deicing/antiicing operations occur, the only means of limiting $\mathrm{AD} / \mathrm{AF}$ contamination of surface and ground waters while ensuring adequate safety is the cancellation of flights. Decisions made in this dichotomous regulatory environment are often predicated on the costs associated with limiting contaminated effluent discharges. The purpose of this paper is to propose the means to facilitate the decision making process with respect to $\mathrm{AD} / \mathrm{AF}$ applications and subsequent stormwater discharges by suggesting an initial design paradigm for the development of a spatial decision support system (SDSS) with which managers can model the mechanisms by which aircraft deicing/anti-icing fluids enter surface waters as pollutants. Using the proposed SDSS to model $\mathrm{AD} / \mathrm{AF}$ effluents, decision makers could better estimate those costs associated with exceeding regulatory guidelines. Further, the ability to generate outcomes within the context of this economic/environmental quid pro quo will provide the manager a range of options with which to make determinations regarding the costs and corresponding implications of the application of AD/AF's. Thus, the SDSS would provide the means with which to explore mitigation opportunities and to reduce the costs of discharging wastewaters containing deicing/anti-icing chemicals.
\end{abstract}

\section{INTRODUCTION}

The Fokker 28-4000 swung into position at the end of LaGuardia's runway 13. Twice before pushback, ground crews had applied a glycolbased fluid, a Type I deicer, to the wings and fuselage of USAir's Flight 405. But with 35 minutes having elapsed since the last application - an interval greater than three times that considered safe - a layer of snow and ice had again accreted on the aircraft's wings. The captain eased the thrust levers forward; the Rolls Royce Speys spooled to full power; Flight 405 began to roll. The landing gear was stiff with cold and the impact of the tires hitting ruts in the packed snow jolted the Fokker's 51 occupants. As the aircraft's momentum increased, the first officer called the V-speeds: V1; then, VR, but 11 knots too early. The additional weight and lift-killing effect of ice on the wings made it impossible to gain much altitude, and the Fokker struggled to leave ground-effect. Abruptly, the left wing stalled and dipped. Its tip scraped the concrete about 4000 feet upwind of the liftoff point. As Flight 405 lost altitude, its wheels bit deeply into the soft earth along the side of the runway. The aircraft struggled back into the air, but the left wing again lost lift and dropped. This time the tip caught a row of lights, then sliced through a building. The Fokker cart-wheeled, breaking-up as it somersaulted over the 15 foot berm that delineated the airport perimeter. The aft fuselage disintegrated in flames. Flight 405 came to rest upside down in the frigid darkness of Bowery Bay. Twenty-seven people died in the icy waters; many drowned while strapped to their seats.

This accident, which occurred just before 9:30 PM on March 23, 1992, underscores the critical nature of the application of deicing fluids to aircraft. The National Transportation Safety Board (NTSB) (1993) attributed probable causes of the accident in part to "... the failure of the airline industry and the Federal Aviation Administration to provide flight crews with procedures, requirements and criteria compatible with the departure delays in conditions conducive to airframe icing . . ." (p. 77). The crash of USAir's Flight 405 with the 
concomitant criticism of the Federal Aviation Administration (FAA) proved a seminal event. It engendered the regulations, promulgated by the FAA, requiring the liberal application of aircraft deicing/anti-icing fluids (AD/AF's) during winter operations (DOT, 1996).

Application of aircraft deicing/anti-icing fluids is governed by the rules and regulations of the Federal Aviation Administration and the Environmental Protection Agency (EPA). These promulgations are often conflicting with diametric or even mutually exclusive goals (Mericas \& Wagoner, 1994; DOT, 1996; Betts, 1999). The FAA encourages the liberal application of $\mathrm{AD} / \mathrm{AF}$ 's to prevent the accumulation of ice that causes horrifically fatal crashes. The public strongly endorses and supports this policy (DOT, 1996). The EPA attempts to restrict the use of $\mathrm{AD} / \mathrm{AF}$ 's to prevent the introduction of pollutants into ground and surface waters. The public strongly endorses and supports this policy (Angelo, 1996). Caught in the middle is the airport manager who, under FAA regulations, must provide adequate deicing opportunities to departing flights, and who, under EPA guidelines, must institute and adhere to a plan, a Stormwater Pollution Prevention Plan (SWPPP), for containing and controlling the AD/AF's used to comply with the FAA requirements (EPA, 1992; EPA, 1993; Mericas \& Wagoner, 1994; DOT, 1996).

Alternatives to the use of $\mathrm{AD} / \mathrm{AF}$ 's are limited and often neither efficacious nor costeffective (Mericas \& Wagoner, 1994). Similarly, according to Barash, Covington, and Tamulonis (2000), the options for containment, control and processing (e.g., recycling) of spent $\mathrm{AD} / \mathrm{AF}$ 's are few and expensive. Further, these latter technologies are frequently so immature as to be either largely untested or only marginally effective (Mericas \& Wagoner, 1994; Barash et al.). Other alternatives, such as canceling flights or closing an airport exist, but are both costly and inconvenient. Shutting-down a major airport causes flights to be diverted and canceled at other airports producing repercussions that reverberate throughout the air traffic system.

Attempts to litigate, legislate, and promulgate away the problems associated with the application of $\mathrm{AD} / \mathrm{AF}$ 's have only served to exacerbate the aforementioned circumstances. The problem is so complex that the EPA preempted its own regulations by stating that, in order to assure adequate deicing of aircraft, it would ignore the discharge of airport waters containing excessive amounts of $\mathrm{AD} / \mathrm{AF}$ contaminants (DOT, 1996). This abrogation of the agency's congressional mandate lasted only briefly, however, as EPA regulators, becoming alarmed at the amount of deicing fluids that were being used, soon rescinded their rescindment. Abruptly, airlines and airport operators found themselves without regulatory guidance.

Because airlines currently operate to make a profit, and on a very small profit margin at that, decisions regarding the use of $\mathrm{AD} / \mathrm{AF}$ 's are inextricably linked to costs of operation. Of necessity, those managing airport facilities will assess user airlines any unsubsidized costs associated with the control or reduction of $\mathrm{AD} / \mathrm{AF}$ 's in discharges to surface waters (Mericas \& Wagoner, 1994; McNerney, 1994). In turn, the airlines will "charge through" any costs to their passengers, and so, it is the consumer who ultimately pays for adherence to the EPA's regulation of airport effluents (Barash et al., 2000). Consequently, the costs associated with improving effluent quality are intrinsic to any decision regarding the reduction of $\mathrm{AD} / \mathrm{AF}$ 's in stormwater discharges and thus significant to airport and airline management as well as the consumer of aviation.

The interrelationship of these disparate and conflicting issues is the reason that Betts (1999) referred to the use of AD/AF's as a "classic environmental problem" (p. 212). How can decision makers, in the context of this confounding regulatory environment and these complex circumstances, make soundly based decisions regarding the singular question: What will be the typical costs of adherence to current and possibly forthcoming EPA regulations governing the release of $\mathrm{AD} / \mathrm{AF}$-contaminated effluents into surface waters? The answer to this fundamental question would facilitate the resolution of related, secondary questions, including: What are the economics of canceling flights in comparison to the costs associated with reducing or eliminating effluents containing anti-icing and deicing fluids? Will EPA 
guidelines, both current and future, necessitate a restriction of flight operations to prevent exceeding $\mathrm{AD} / \mathrm{AF}$ discharge limits and ensure the quality of ground and surface waters? Which airports are most likely to become noncompliant with their EPA-mandated Stormwater Pollution Prevention Plans and at what costs? To develop insight into questions such as these and provide decision makers with a useful tool with which to better assess and manage the problems associated with $\mathrm{AD} / \mathrm{AF}$ discharges, a spatial decision support system (SDSS) would be useful. For example, the proposed SDSS could be used to predict an airport's potential for exceeding effluent guidelines and to determine the economic impact of compliance with EPA regulations. Similarly, airport managers could use the proposed spatial decision support system to predict the potential for exceeding its SWPPP, determine current and future costs associated with SWPPP compliance, and, based on these costs, determine alternative strategies to reduce $\mathrm{AD} / \mathrm{AF}$ discharges to an acceptable level.

\section{SIGNIFICANCE OF THE PROBLEM}

\section{The Necessity of AD/AF Applications}

During a 14-year period, between 1982 and 1996, aircraft icing caused six accidents that killed 203 people (DOT, 1996). Although the majority of these accidents and over half the fatalities occurred in the decade preceding 1992, it was the crash of USAir's Flight 405 that produced the first substantial criticism of the FAA with respect to its policies regarding the deicing and anti-icing of aircraft. The fact that, during winter airport operations, the application of $\mathrm{AD} / \mathrm{AF}$ 's is critical to flight safety has not escaped the attention of paying passengers. According to a 1996 Department of Transportation (DOT) Report, "Aircraft accidents [have] raised public concern about the safety of aircraft during icing conditions" (p. 1).

In listing probable causes of the Flight 405 crash, the National Transportation Safety Board (1993) criticized the Federal Aviation Administration for its failure " . . . to provide flight crews with procedures, requirements and criteria compatible with the departure delays in conditions conducive to airframe icing ..." (p. 77). Three years after release of the 1993 NTSB report, the DOT's Office of the Inspector General produced an equally critical indictment of the FAA's failure to meet its obligation to ensure safety of flight. The OIG (1996) stated that the agency's remedial actions and amendments which were implemented in the aftermath of the Flight 405 tragedy "... will not eliminate icing-related accidents and incidents" (p. i).

In response to NTSB and DOT criticisms and the public's concern over potentially fatal air crashes, the FAA promulgated, in a regulatory frenzy, the Federal Aviation Regulations (FAR's) currently governing the application of AD/AF's (Barash et al., 2000). These regulations have not only increased the use of deicing/anti-icing fluids, but also made flying safer. This assertion is substantiated by the fact that, since the crash of Flight 405, no fatal airline accidents have been attributed to inadequate application of $\mathrm{AD} / \mathrm{AF}$ 's.

\section{Potential Environmental Impacts}

Evidence supporting the contention that excessive AD/AF's are being discharged into U.S. surface waters is abundant. For example, consider the volume of AD/AF's used. Fifty-two million liters or approximately 13,740,000 gallons of AD/AF's are used annually in North America; Worldwide, airlines apply about a half billion gallons of AD/AF's (Cancilla, Martinez, \& VanAggelen, 1998). According to Mericas and Wagoner (1994) "The ADF volume required to deice a typical large passenger jet (approximately $3785 \mathrm{~L}$ [1000 gal]) has a $\mathrm{CBOD}_{5}$ [five day carbonaceous biochemical oxygen demand] equivalent to the daily domestic wastewater generated by 5000 people" (p. 40).

That surface waters receive much of this $\mathrm{AD} / \mathrm{AF}$ is unquestionable. Transport Canada estimates that nearly $50 \%$ of $\mathrm{AD} / \mathrm{AF}$ 's drain directly into stormwater runoff (Mericas \& Wagoner, 1994). The EPA estimates that the annual volume of $\mathrm{AD} / \mathrm{AF}$-contaminated stormwater is between 300 million and 1.4 trillion gallons with a yearly average of approximately 7 billion gallons (Barash et al., 2000). Further, of the airports surveyed by the EPA for the Airport Deicing Operations Summary (2000), 50\% discharged AD/AFcontaminated stormwater directly into surface 
waters, with no means of mitigating the impact of the effluent on surface waters (Barash et al., 2000). Another $42 \%$ discharged $\mathrm{AD} / \mathrm{AF}$ 's into both surface waters and publicly-owned wastewater treatment plants. In total, more than $92 \%$ of the airports surveyed discharge $\mathrm{AD} / \mathrm{AF}$ contaminated effluents into surface waters. Safferman, Siruvalure, and Foppe (1998) report that "Even if the deicing fluids are diluted 99.9\% in storm water or in a receiving stream ... the uncontrolled release of these compounds can have a severe impact on the environment" ( $p$. 11).

Several large U.S. airports discharge AD/AF's directly into surface waters: Portland International Airport which discharges into the Willamette River through the Columbia Slough; Milwaukee's General Mitchell International Airport from which effluents drain directly into Lake Michigan; Logan International Airport which discharges untreated wastewaters containing AD/AF's directly into Boston Harbor; Baltimore-Washington International Airport from which effluents enter Chesapeake Bay, and; Minneapolis-St. Paul International Airport (where a single carrier, Northwest Airlines typically uses 800,000 gallons of deicing fluid in a single winter) which releases glycol runoff directly into the Minnesota River (Corsi, Booth, \& Hall, 2001; Betts, 1999; Guterman, 1999; Angelo, 1996; Bremer, 1993).

According to the EPA (Barash et al., 2000):

... airport deicing operations can result in [negative] environmental impacts. In addition to potential aquatic life and human health impacts from the toxicity of deicing and anti-icing chemicals, the biodegradation of propylene and or ethylene glycol (i.e., the base chemical of deicing fluid) in surface waters . . . can greatly impact water quality, including significant reduction in dissolved oxygen (DO) levels. Reduced DO levels can ultimately lead to fish kills. [Additionally,] . . . fish kills caused by [airport] discharges ... may [also] be due to ... the aquatic toxicity of deicing chemicals" (p. 1-2).

A number of field studies support the foregoing statements. For example, tolyltriazoles, an $\mathrm{AD} / \mathrm{AF}$ additive that has been found in airport ground water, has the potential to be extremely toxic (Betts, 1999; Guterman, 1999; Cancilla et al., 1998). In another study, Koryak, Stafford, Reilly, Hoskin, and Haberman (1998) found that, when introduced into an adjacent watershed, glycol and urea deicers created a strong biochemical oxygen demand (BOD) in the waters, stimulating the growth of dense biological slimes on the streambed. According to these researchers, "Invertebrate communities in waters influenced by airport runoff were severely stressed and ... . [the] fishery of the watershed was also impaired" (p. 287). Turnbull and Bevan (1995) identified similar ecological impacts resulting from the discharge of $\mathrm{AD} / \mathrm{AF}$ compounds from Newcastle Airport in the Ouseburn, a tributary of the Tyne River in England.

In other articles, Guterman (1999) cites evidence correlating heavy deicing operations at General Mitchell International Airport in Milwaukee with increased aquatic mortality in a stream carrying effluents from the airport to Lake Michigan; Cancilla, Baird, Geis, and Corsi (2003), found that ". . . field and lab studies indicate that additives, other than glycols, used in aircraft deicing fluids can be found in aquatic systems and may be of greater risk than previously believed" (p. 134). According to Jia, Bakken, Breedveld, Aagaard, and Frostegärd (2006), one such additive, benzotriazole, decomposes slowly, retards, through interaction, the degradation of organic substrates found in airport runoffs (e.g., acetate, formate, glycol and toluene), and, as a powerful toxic, impairs the health of soil ecosystems. Empirical evidence compiled during research conducted by Bielefeldt, Illangasekare, and LaPlante (2004) also suggests that glycol, itself, contributes to soil compaction and, consequently, reduces the ability of soils to percolate and filter airport runoff. Thus, the act of deicing aircraft may, in itself, increase the likelihood that aircraft $\mathrm{AD} / \mathrm{AF}$ chemicals will enter surface waters.

Concerns over the consequences of the discharge of airport effluents containing deicer chemicals have resulted in lawsuits against airports and managing authorities (Betts, 1999; Amicus Journal, 2000). The National Resource Defense Council (NRDC) filed suit against 
Chicago's O'Hare where “ . . . [managers] had not been sufficiently reporting the use of a . . . deicing chemical called ethylene glycol, which can be harmful, and even deadly ... " (Amicus Journal, 2000, p. 46; see also Croft, 2000). The US-Civil Aviation Watch, in concert with the NRDC and several other groups, have filed suit against Baltimore-Washington International Airport (BWI) over the discharge of effluents containing $\mathrm{AD} / \mathrm{AF}$ chemicals (Washington Post, 1998; Croft, 2000). The coalition cited violations of the Clean Water Act and the airport's Storm Water Pollution Prevention Plan.

The implications of these lawsuits with respect to environmental regulations are significant. For example, that certain airports discharge unacceptable quantities of $\mathrm{AD} / \mathrm{AF}$ 's into surface waters, even in excess of that allowed under existing regulations, is implicit in both litigations. A second implication is that airports, being responsible for their own oversight, may not adequately monitor effluents. A third is that airport SWPPP's may have been haphazardly developed, without accountability for the information upon which they were justified. And finally, that regulations are not uniform, varying from one state to another, and, although penalties for noncompliance with existing laws may be costly, enforcement is often uneven and seldom rigorous (Barash et al., 2000; Amicus Journal, 2000).

\section{Economic Impacts}

Airports incur capital costs associated with implementation of technologies for the mitigation of $\mathrm{AD} / \mathrm{AF}$ pollution as well as operating costs for collection, treatment and disposal of $\mathrm{AD} / \mathrm{AF}$-contaminated waters. In fact, McNerney (1994) states that “. . . major expenses at airports today are the cost of infrastructure and the mitigation of environmental concerns" (p. 680). Barash et al. (2000) note that ". . . much of the cost of capital improvements [associated with the application of the AD/AF's] are likely to be passed-through to the airlines as higher fees or to the passenger in the form of passenger facility charges (PFCs)" (p. 1-5). The fee an airport assesses an airline to recover the costs of collection, treatment and disposal of contaminated stormwater may be double the cost of the $\mathrm{AD} / \mathrm{AF}$ fluid, effectively tripling the carrier's cost of deicing an aircraft (Betts, 1999). Generally operating on a narrow margin of profit, airlines, in turn, pass costs through to the passenger in the form of higher ticket prices. Ultimately, therefore, the consumer, the paying passenger, is the one who will likely bear the cost of both the use of deicing fluid, applied to ensure a safe flight, and the expense of preventing environmental degradation.

Airports discharging directly into surface waters are the most likely to be impacted by stricter enforcement of existing EPA guidelines or enactment of more stringent regulations. Because many lack the equipment to store, mix and deliver multi-strength deicing fluids, these facilities are also more likely to use a concentration of chemicals effective in the most severe weather conditions (Barash et al., 2000). Further, such airports are less likely to be in a position to purchase the more sophisticated equipment that reduces the amount of $\mathrm{AD} / \mathrm{AF}$ applied and make modification to the facility's physical plant to comply with more stringent effluent controls. Thus, these will be the airports most affected by the pressures of stricter enforcement, more stringent EPA guidelines, and the projected increase in demand for air transportation. Airports discharging directly into surface waters will be the most likely to cancel flights to remain compliant with environmental regulations. Under what circumstances will such cancellations be necessary? What are the costs associated with such cancellations? Given that the cancellation of flights reduces airline profits, what mitigation technologies might become economically justifiable in lieu of canceling flights or temporarily closing an airport? These are the questions the proposed SDSS would inform. The answers so derived have the potential to impact the gamut of those engaged in air transportation and commerce, including airport and airline managers and the aviation consumer.

\section{SDSS METHODOLOGY}

\section{SDSS Design}

The proposed spatial decision support system could be used to model airport $\mathrm{AD} / \mathrm{AF}$ outfall concentrations, predict the extent of 
opportunity costs lost through compliance, and suggest which mitigation alternatives are most desirable given the economic outcomes. The SDSS would be based on GIS software, hydrological modeling extensions and scripting to provide a graphical user interface (GUI). Components would include: (1) geographic information system (GIS) software (e.g., Environmental Systems Research Institute's ArcInfo or ArcView programs) to provide management and database storage of spatial (locational) and aspatial (attribute) data; (2) a modeling management and database module (MMDM); (3) a graphical user interface (GUI), manipulated via computer mouse and keyboard, and; (4) the means of generating and displaying outcomes via a monitor and printer. (See Figure 1.)

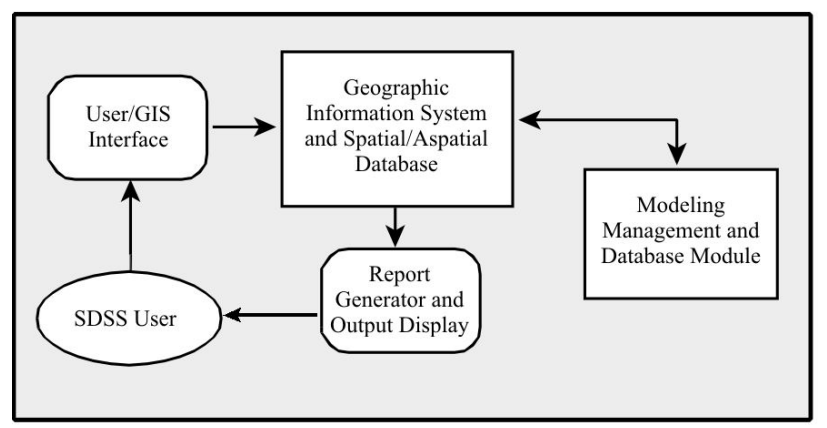

Figure 1. Organization of the proposed SDSS.

\section{SDSS Components and Construction}

In its spatial database, the GIS would store the locations of deicing operations and airport slope and terrain attributes. Information regarding the number and volume of $\mathrm{AD} / \mathrm{AF}$ applications, which would be stored in the aspatial database, could be adjusted according to anticipated weather conditions. Effluent concentrations would be calculated in the MMD module using existing water quality software (e.g., the EPA's BASINS which models discharges from point and non-point sources) and predicted, based on terrain and slope information, at the airport's outfall. The user could enter anticipated conditions to derive outcomes for comparison in determining maximum $\mathrm{AD} / \mathrm{AF}$ volumes given meteorological variables, number and types of flights and EPA pollutant loading criteria. The assumption would be that FAA and EPA regulations are fixed (at any given time) and that airports strive to achieve conformance to these guidelines. Costs would be computed based on the preceding parameters.

In a publication known as the "Green Book", the Bureau of Transportation Safety (BTS) prints monthly statistics for all large certificated carriers that include measures of capacity (available seat miles), capacity usage (revenue seat miles), enplanements, departures, etc. In its "Blue Book," the BTS provides similar statistics for small certificated, regional and commuter airlines. The BTS also publishes an annual record of airline service to individual airports in the Airport Activity Statistics. Costs incurred by the airlines as the result of $\mathrm{AD} / \mathrm{AF}$ applications are available from the EPA and the Air Transport Association of America. This data would be useful in determining at what point it will be necessary to cancel flights, the costs of such cancellations and what environmental impact mitigation alternatives may become viable in lieu of reduced or restricted flight operations. Given that many airports have no means of mitigation and discharge effluents directly into surface waters (approximately 50\% of those surveyed by the EPA) it is generally accepted that the only alternative to exceeding effluent guidelines at these facilities is the cancellation of flights (Barash et al., 2000). Thus, the opportunity costs associated with flight cancellations would be computed using data available from a variety of sources.

The term, "pollutant loading," refers to the concentration of pollutants in a volume of water. The EPA developed pollutant loading criteria as a preliminary step to the promulgation of effluent guidelines regulating the discharge of airport wastewaters containing AD/AF's. Although numerous sources (e.g., leaking equipment, spills and aircraft runoff) may contribute to the total pollutant load, the EPA discounted these as relatively minor when compared to the de-icing pads where AD/AF's are applied. Consequently, the EPA ". . . developed pollutant loading estimates for the industry based solely on estimates of the average volume of fluid sprayed and considered all other sources of ADF discharges to be negligible" (Barash et al., 2000, p. 11-2). The proposed SDSS would rely upon published EPA pollutant loading criteria to determine $\mathrm{AD} / \mathrm{AF}$ 
concentration limits in airport effluents. The concentration of $\mathrm{AD} / \mathrm{AF}$ 's in the airport's outfall would provide the means of determining under what conditions and circumstances an airport's SWPPP limits would be reached.

Additional data available from the EPA would also be used in designing the SDSS. For example, at airports where the deicing and antiicing runoff is not contained, $\mathrm{AD} / \mathrm{AF}$ 's enter the environment following application to aircraft and paved airport surfaces such as runways, roadways, taxiways and gate areas. Barash et al. (2000) assert that " . . . approximately $80 \%$ of the Type I deicing fluids that are applied to aircraft fall to the pavement" (p. 10-1). Using this value, the SDSS would be capable of computing $\mathrm{AD} / \mathrm{AF}$ pollutant loading based on amount of fluids applied, airport terrain and surface types between the point of application and the effluent outfall.

Unless authorized by a National Pollutant Discharge Elimination System (NPDES) permit, point source discharges of pollutants to navigable waters are expressly prohibited by the 1972 amendments to the Federal Water Pollution Control Act (also referred to as the Clean Water Act or CWA). The EPA (1993) defines a point source as: " . . . any discernible, confined and discrete conveyance, including but not limited to, any pipe, ditch, channel, tunnel, conduit, well, discrete fissure, container, . .." from which pollutants are or may be discharged (p. 52). NPDES Stormwater Discharge Permit regulations require that airports conducting airport surface and/or aircraft deicing/anti-icing operations must obtain a stormwater discharge permit. These airports and/or airlines “ . . . must apply for a storm water discharge permit for locations where deicing chemicals are applied. . . [including] but . . . not limited to, runways, taxiways, ramps and areas used for the deicing of airplanes" (EPA, 1992, p. 11). These permits establish effluent limitations for various pollutants and require that airports monitor discharges to detect excessive levels of pollutants. Most often airports monitor $\mathrm{BOD}_{5}$ and/or glycols (Barash et al., 2000). Therefore, in order to make meaningful comparisons to the levels prescribed in EPA guidelines and more specifically, a given airport's SWPPP, the SDSS would be designed to predict point source
$\mathrm{AD} / \mathrm{AF}$ pollution based on topology, precipitation, volume of $\mathrm{AD} / \mathrm{AF}^{\prime}$ 's applied, number and types of flights with respect to EPAdeveloped pollutant loading criteria in terms of $\mathrm{BOD}_{5}$ and/or glycols. The determination of the point at which maximum allowable $\mathrm{AD} / \mathrm{AF}$ concentration is reached at the outfalls would provide the basis for deriving the opportunity costs of flight cancellations and evaluating mitigation options.

\section{CONCLUSION}

The current operational environment is complex. Airport managers are obligated under FAA regulations to provide adequate $\mathrm{AD} / \mathrm{AF}$ facilities for winter operations while constrained by EPA guidelines restricting the concentration of $\mathrm{AD} / \mathrm{AF}$ 's in airport effluents. Airport and airline managers are driven to generate profits, but burdened with the costs of environmental mitigation. That significant quantities of $\mathrm{AD} / \mathrm{AF}$ 's are entering surface waters is indisputable.

Expectations are that glycol will continue to be the primary constituent of AD/AF's, and further, that these fluids will be in use for the deicing and anti-icing of aircraft for the foreseeable future (Mericas \& Wagoner, 1994). Current trends and forecasts suggest that, unless factors alter significantly, increasing amounts of aircraft deicing and anti-icing fluids will flow into surface waters (Angelo, 1996; Rusten, Wien, \& Skjefstad, 1996; Betts, 1999). EPA data indicate that deicer usage has significantly increased over the last two decades, and projections suggest that air travel will continue to increase. Correlating to FAA predictions of increased air traffic is the expectation that quantities of glycol-based AD/AF's applied to aircraft will also become greater (Mericas \& Wagoner, 1994; Rusten et al., 1996). Larger aircraft (e.g., the Airbus A380) will require still greater quantities of $\mathrm{AD} / \mathrm{AF}$ 's to safely fly in wintry precipitation. With this in mind consider: "The $[\mathrm{AD} / \mathrm{AF}]$ fluid required to deice one 747 is equivalent to the daily effluent from 5,000 homes ..." (Angelo, 1996, p. 10). And, even as the pressures to increase $\mathrm{AD} / \mathrm{AF}$ usage become greater, the EPA is considering issuance of more stringent guidelines. 
Given that mitigation of environmental pollution is a major expense at airports, McNerney (1994) notes that a GIS “ . . . can provide significant improvements to the way airport management . . . [is] conducted today" (p. 681). The purpose of this proposal has been to suggest the design of a GIS-based SDSS for the purpose of determining the opportunity costs associated with airport deicing operations. The ability to project costs associated with $\mathrm{AD} / \mathrm{AF}$ applications would also be useful in exploring various mitigation strategies. 


\section{REFERENCES}

Amicus Journal (2000). The Dangers of Deicing. The Amicus Journal, 21, 46.

Anatta (Author's full name) (2000). Deicing Forecasts Unclog LaGuardia and O'Hare Airports. http://www.ucar.edu/communications/quarterly/spring97/deicing.html [On-line]. Available: www.ucar.edu/

Angelo, W. J. (1996). Deicing is a Hot Problem: Odor and Runoff Problems at U.S. Airports. Engineering News-Record, 236, 10.

Barash, S., Covington III, J., \& Tamulonis, C. (2000). Preliminary Data Summary: Airport Deicing Operations (Rep. No. EPA 821-R-00-001). Washington, D.C.: United States Environmental Protection Agency; Office of Water.

Betts, K. S. (1999). Airport Pollution Prevention Takes Off. Environmental Science and Technology, 33, 210-212.

Bielefeldt, A. R., Illangasekare, T., \& LaPlante, R. (2004). Bioclogging of Sand due to Biodegradation of Aircraft Deicing Fluid. Journal of Environmental Engineering, 130, 1147-1153.

Bremer, Karl (1993, October). The Double Deicing Dilema. Airport Magazine.

Cancilla, D. A., Baird, C. J., Geis, S. W., \& Corsi, S. R. (2003). Studies of the Environmental Fate and Effect of Aircraft Deicing Fluids: Detection of 5-methyl-1h-benzotriazole in the Fathead Minnow (Pimephales Promelas). Environmental Toxicology \& Chemistry, 22, 134-140.

Cancilla, D. A., Martinez, J., \& VanAggelen, G. C. (1998). Detection of Aircraft Deicing/Anti-icing Fluid in a Perched Water Monitoring Well at an Interantional Airport. Environmental Science and Technology, 32, 3834-3835.

Corsi, S. R., Booth, N. L., \& Hall, D. W. (2001). Aircraft and Runway Deicers at General Mitchell International Airport, Milwaukee, Wisconsin: Biochemical Oxygen Demand and Dissolved Oxygen in Receiving Streams. Environmental Toxicology \& Chemistry, 20, 1474-1483.

Croft, John W. (2000, October 23). 10-Year Airport Outlook: Dearth of New Runways. Aviation Week \& Space Technology, 153, 74-75.

DOT (1996). Report on Federal Aviation Administration Deicing Program (Rep. No. E5-FA-7-001). Washington, D.C.: Department of Transportation, Office of the Inspector General.

EPA (1992). NPDES Stormwater Program: Question and Answer Document Volume 1 (Rep. No. EPA 833-F-93-002). Washington, D.C.: United States Environmental Protection Agency; Office of Water.

EPA (1993). NPDES Stormwater Program: Question and Answer Document Volume 2 (Rep. No. EPA 833-F-93-002B). Washington, D.C.: United States Environmental Protection Agency; Office of Water.

Guterman, L. (1999). Toxic Takeoffs: Aircraft De-icers hold a hidden hazard. New Scientist, 161, 7.

Jia, Y., Bakken, L. R., Breedveld, G. D., Aagaard, P., \& Frostegärd, Ä. (2006). Organic Compounds That Reach Subsoil May Threaten Groundwater Quality; Effect of Benzotriazole on Degradation Kinetics and Microbial Community Composition. Soil Biology \& Biochemistry, 38, 2543-2556.

Koryak, M., Stafford, L. J., Reilly, R. J., Hoskin, R. H., \& Haberman, M. H. (1998). The Impact of Airport Deicing Runoff on Water Quality and Aquatic Life in a Pennsylvania Stream. Journal of Fresh Water Ecology, 13, 287-298.

McNerney, M. (1994). The Use of Geographical Information Systems at U.S. Airports. In URISA '94 (pp. 680-688). Park Ridge, Illinois: Urban and Regional Information Systems Association. 
Mericas, D. \& Wagoner, B. (1994). Toxic Takeoffs: Aircraft De-icers Hold a Hidden Hazard. Water Environment and Technology, 6, 38-43.

NTSB (1993). Aircraft Accident Report: Takeoff Stall in Icing Conditions USAir Flight 405 (Rep. No. NTSB/AAR-93/02). Washington, D.C.: National Transportation Safety Board.

Rusten, B., Wien, A., \& Skjefstad, J. (1996). Spent Aircraft Deicing Fluid as External Carbon Source for Denitrification of Municipal Wastewater: From Wastewater to Beneficial Use. In The $51^{\text {st }}$ Industrial Waste Conference.

Safferman, S. I., Siruvalure, G. S., \& Foppe, L. E. (1998). Deicing Fluid Treatment in Batch-Loaded Aerobic Fluidized Bed Reactor. Journal of Environmental Engineering, 124, 11-15.

Turnbull, D. A. \& Bevan, J. R. (1995). The Impact of Airport Deicing on a River: The Case of the Ouseburn, Newcastle Upon Tyne. Environmental Pollution, 88, 321-332.

Washington Post (1998, January 9). BWI Threatened with Environmental Lawsuit. Washington Post, The, pp. Metro. 